\title{
Fasülye Turşusu Salamurasının Temel Kimyasal ve Mikrobiyolojik Özelliklerinin Belirlenmesi
}

\section{Determination of Basic Chemical and Microbiological Properties of Pickled Beans Brine}

\author{
Hümeyra Odabaşa, ${ }^{\mathrm{a}, 1}$ Banu Metinn ${ }^{\mathrm{a}, \mathrm{b}, 2^{*}}$ \\ a İstanbul Sabahattin Zaim Üniversitesi, Mühendislik ve Doğa Bilimleri Fakültesi, Gıda Mühendisliği Bölümü, İstanbul, Türkiye \\ ${ }^{\mathrm{b}}$ Gıda ve Tarım Uygulama ve Araştırma Merkezi, İstanbul Sabahattin Zaim Üniversitesi, İstanbul, Türkiye \\ İstanbul Sabahattin Zaim Üniversitesi Fen Bilimleri Enstitüsü Dergisi (2020) 2 (3): 32-34 \\ https://doi.org/10.47769/izufbed.763347 \\ (iD) $\mathrm{RRCID}_{1} 0000-0003-4815-9507 ;{ }^{2} 0000-0002-3203-0058$
}

\begin{tabular}{l}
\hline YAYIN BİLGİSI \\
\hline Yayın geçmişi: \\
Gönderilen tarih: 03 Temmuz 2020 \\
Kabul tarihi:01 Kasım 2020 \\
\hline Anahtar kelimeler: \\
Turşu \\
Yeşil fasulye \\
Salamura \\
Laktik asit bakterileri \\
Fermantasyon \\
Keywords: \\
Pickle \\
Green beans \\
Brine \\
\hline
\end{tabular}

\begin{abstract}
ÖZET
Fasulye turşusu, Karadeniz bölgesine ait geleneksel gıdalardan biridir. Bu çalışmada, literatürde yeteri kadar bilimsel bir veri bulunmayan fasulye turşusunun temel kimyasal ve mikrobiyolojik özellikleri ile ilgili bilgi edinmek amaçlanmıştır. Bu çalışmada, geleneksel yöntemler ile elde edilen 4 turşu numunesi kullanılmıştır. Turşuların yapımında Trabzon ilinin Of ilçesine ait köylerden toplanan fasulyeler kullanılmıştır. Turşu salamura örneklerinin $\mathrm{pH}$ değerleri 3.40-3.65, tuz miktarları ise \%3.98-\%5.89 arasında bulunmuştur. Mikrobiyolojik analizler neticesinde, salamura örneklerinde laktik asit bakterilerinin 2.30-4.37 $\log \mathrm{kob} / \mathrm{mL}$, toplam mezofilik aerobik bakterilerin 2.33-4.34 $\log \mathrm{kob} / \mathrm{mL}$, mayaların ise 2.00-4.33 $\log \mathrm{kob} / \mathrm{mL}$ arasında olduğ gözlenmiştir. Kimyasal ve mikrobiyolojik bulgular, literatürdeki diğer turşu çalışmaları ile uyumludur.

\section{ABSTRACT}

Bean pickles are one of the traditional foods of the Black Sea region. In this study, it is aimed to gain information on the basic chemical and microbiological properties of pickled beans, about which insufficient scientific data is present in the literature. In this study, four pickle samples produced using traditional methods were used. The pickles were produced using beans collected from the villages of Of district of Trabzon. The $\mathrm{pH}$ values of brine samples were found between 3.40-3.65, and the salt amounts were between $3.98 \%$ and 5.89\%. Microbiological analysis showed that lactic acid bacteria were between $2.30-4.37 \log \mathrm{cfu} / \mathrm{mL}$, total mesophilic aerobic bacteria were between 2.33-4.34 $\log \mathrm{cfu} / \mathrm{mL}$, and yeasts were between $2.00-4.33 \log \mathrm{cfu} / \mathrm{mL}$ in brine samples. The chemical and microbiological findings are in concordance with other pickle studies in literature.
\end{abstract}

\section{Giriş}

Fermantasyon uzun yıllardır var olan bir gida üretim ve koruma yöntemidir. Fermente ürünler bitkisel ve hayvansal besinlerin doğal yolla kendiliğinden veya starter kültür yardımıyla fermantasyonu sonucu elde edilen gidalardır (Karaçıl ve Acar, 2013). Fermantasyon sonucunda besin değeri yüksek, çok yönlü, farklı tat ve aromada, ekonomik olarak değerli, uzun süre muhafaza edilebilir ve emsalsiz ürünler elde edilmektedir (Tokatlı ve ark., 2012). Meydana gelen fermantasyonun çeşidi glikozun parçalandığ son ürüne göre değişmektedir: Örneğin, glikoz etil alkole dönüşürse meydana gelen fermentasyon etil alkol, laktik asit oluşturursa laktik asit fermantasyonu olarak adlandırılmaktadır (Elmacı ve ark., 2019). Laktik asit fermantasyonunda laktik asit bakterileri (LAB) etkin bir şekilde görev almaktadır. Fermente gidalarda Lactobacillus bulgaricus, Lactobacillus plantarum, Leuconostoc mesenteroides vb. laktik asit bakterilerine s1k rastlanılmaktadır (Elmac1 ve ark., 2009). Yaygın olarak bilinen ve tüketilen fermente ürünlere yoğurt, ekmek, turşu, sirke, peynir, kefir, fermente et ürünleri ve şarap örnek olarak verilebilir (Akman, 1987).

Turşu, sebzelerin veya meyvelerin belirli tuz konsantrasyonuna sahip salamuralarda laktik asit fermantasyonu sonucunda elde edilen bir üründür (Karagöz ve ark., 2017). Turşunun muhafaza süresinin uzun olmasında iki önemli etken bulunmaktadır, bunlar tuz konsantrasyonu ve laktik asit oluşumudur (Tokatlı ve ark., 2019). Turşuda bulunan mikroorganizma çeşitliliği üzerinde tuz, uygun sıcaklık ve düşük O2 konsantrasyonu etkilidir (Elmacı ve ark.,

\footnotetext{
* Sorumlu yazar

E-mail adresi: banu.metin@izu.edu.tr (Banu Metin)
} 
2019). Turşunun tadının ve aromasının oluşmasında, uzun süre bozulmadan muhafaza edilebilmesinde LAB etkilidir. $\mathrm{LAB}$, ortam $\mathrm{pH}$ değerini 4.5 'in altına düşürerek patojen mikroorganizmalara karşı koruyucu etki göstermektedir (Tokatlı ve ark., 2012).

Fasulye, dünyada ekim alanı ve üretim yönünden ilk sırada bulunan sebze ürünüdür (Anlarsal ve ark., 2000). Türkiye'de ise fasulye ekim alanı ve üretimi, mercimek ve nohut gibi baklagillerden sonra üçüncü sırada yer almaktadır (Anlarsal ve ark., 2000). Türkiye önemli bir taze fasulye yetiştiricisidir ve en yaygın ekim Samsun ilinde yapılmaktadır (Ulukapı ve Onus, 2013). Fasulye daneleri, karbonhidrat, kalsiyum, demir ve fosforca zengin olmasının yanında, yüksek oranda bitkisel protein içermektedir. $\mathrm{Bu}$ proteinlerin amino asit kompozisyonu, hayvansal proteinlere yakınlık göstermektedir. $\mathrm{Bu}$ nedenle, fasülye, vegan ve vejetaryen bireyler tarafından, protein gereksinimlerini karşılamak üzere tercih edilmektedir (Çavuşoğlu ve Akçin, 2007). Fasulye, konserve, kurutma gibi çeşitli yöntemlerle muhafaza edilebildiği gibi salamura yöntemiyle laktik asit fermantasyonu sonucu turşu olarak da tüketilebilmektedir. Fasulye turşusu özellikle Karadeniz bölgesinde severek tüketilen geleneksel ürünlerimizden biridir.

Literatürde turşu ile ilgili çalışmalar incelendiğinde sıklıkla salatalık (hıyar), lahana, biber vb. turşu çeşitlerinin araştırmalara konu olduğu görülmektedir. Bu çalışmada, yapılan literatür taramasında hakkında yeteri kadar bilimsel bir veri bulunmadığı görülen fasulye turşusunun, temel mikrobiyolojik ve biyokimyasal özelliklerinin incelenmesi amaçlanmıştır.

\section{Materyal ve Yöntem}

\subsection{Turşu örneklemi}

Bu çalışmada, 4 farklı ev tipi fasulye turşusu kullanılmıştır. Turşuların yapımında, Trabzon ilinin Of ilçesine ait köylerden 2019 yılının eylül ayında toplanan fasulyeler kullanılmıştır. Turşular, geleneksel üretim yöntemine göre, kısa süreli haşlama işleminden sonra, bir kat fasulye bir kat kaya tuzu, sarımsak ve acı biber karışımı olacak şekilde saklama kabına dizilerek, içme suyu eklendikten sonra, serin ve karanlık bir ortamda 30 gün muhafaza edilmek suretiyle elde edilmiştir.

\subsection{Kimyasal analizler}

Turşu örneklerinin salamura sularına $\mathrm{pH}$ ve \% tuz miktar analizi yapılmıştır. pH analizinde Hanna HI 2211 masa tipi pH metre kullanılmıştır. Tuz miktarını tespit ederken Mohr yöntemi (AOAC, 1971) kullanılmıştır. $1 \mathrm{~mL}$ örnek $20 \mathrm{~mL}$ saf su ile seyreltildikten sonra üzerine $1 \mathrm{~mL}$ potasyum kromat (K2CrO4) (Sigma) çözeltisi eklenmiş ve $0.1 \mathrm{~N}$ gümüş nitrat (AgNO3) (Isolab) titre edilmiştir. Elde edilen veriler denklem (1) üzerine yerleştirilerek \% tuz miktarı hesaplanmıştır.

$\%$ Tuz Miktarl $=[(V 2-V 1) \times N \times m E q \times F) / G] \times 100$

$\mathrm{V} 1=$ Şahit numune gümüş nitrat sarfiyatı $(\mathrm{mL})$

$\mathrm{V} 2=$ Esas numunede harcanan gümüş nitrat sarfiyatı $(\mathrm{mL})$

$\mathrm{N}=$ Gümüş nitrat çözeltisinin normalitesi $(0,1 \mathrm{~N})$

$\mathrm{mEq}=\mathrm{NaCl}$ mili ekivalent ağırlığı $(\mathrm{g})$

$\mathrm{F}=$ Gümüş nitrat çözeltisi faktörü

$\mathrm{G}=$ Numuneden alınan örnek miktarı $(\mathrm{mL})$

\subsection{Mikrobiyolojik analizler}

Salamura örnekleri için üç çeşit besiyeri ile çalışılmıştır.
Laktik asit bakterileri için, de Man, Rogosa and Sharpe (MRS) agar, mayalar için Potato Dextrose Agar (PDA) ve toplam mezofilik aerobik bakteri (TMAB) sayımı için Plate Count Agar (PCA) besiyerleri talimatlara uygun şekilde hazırlanmıştır. Hazırlanan besiyeri karışımları otoklavda (Selecta) $121^{\circ} \mathrm{C}^{\prime}$ de 15 dakika sterilize edilmiştir.

Salamura numunesi $(5 \mathrm{~mL})$ ve sterilize edilmiş $45 \mathrm{~mL}$ peptonlu su Stomacher (Bag Mixer) cihazında 120 saniye karıştırıldıktan sonra $100 \mu \mathrm{L}$ alınarak iki paralel olacak şekilde besiyerlerine yayma metodu kullanılarak ekim yapılmıştır. MRS ve PCA besiyerleri için $30^{\circ} \mathrm{C}$ 'de 2 günlük, PDA besiyeri için ise $30^{\circ} \mathrm{C}$ 'de 5 günlük inkübasyon süresi tamamlanan petrilerde oluşan koloniler sayılmıştır. Bu çalışmada, 4 farklı ev tipi fasulye turşusu kullanılmıştır.

\section{Bulgular ve Tartışma}

\subsection{Kimyasal bulgular}

Fasulye turşusu salamura pH değerlerinin 3.40-3.65 aralığında ve ortalama $\mathrm{pH}$ değerinin 3.55 olduğu saptanmıştır (Çizelge 1). Karasu (2006) yaptığı çalışmada turşu örneklerinin $\mathrm{pH}$ sonuçlarını 2.0-6.41 aralığında ve ortalama $3.53 \mathrm{pH}$ değerinde olduğunu tespit etmiştir. Johanningsmeier ve ark. (2004) turşu örneklerinin $\mathrm{pH}$ sonuçlarının 4.28-5.76 pH aralığında değiştiğini bildirmiştir. Yıldız (2011) tarafından turşu örneğinin salamura $\mathrm{pH}$ değerleri 3.39-3.96 aralığında ortalama ise $3.51 \mathrm{pH}$ olarak saptanmıştır. Fasulye turşusu numunelerinde $\mathrm{pH}$ değerlerinin diğer çalışmalarla paralel olduğu gözlenmiştir.

Turşu salamurasında tuz miktarının \%3.98-5.89 arasında değişmekte olduğu, ortalama tuz miktarının ise $\% 4.89$ olduğu görülmüştür (Çizelge 1). Turşu standartlarına (TS-4200, TS4214, TS-11112) göre salamura içerisinde bulunabilecek tuz miktarı turşu yapılan hammadde çeşidine göre değişmekle beraber en çok \%6-7 oranında olabileceği belirtilmiştir (Yıldız, 2011). Fasulye turşusu numunelerinin tuz miktarlarının belirtilen limit içerisinde olduğu görülmektedir. Karasu (2006) aynı çalışmada turşu örneklerinin tuz miktarlarını \%0.39-9.89 aralığında, ortalama \%3.96 olarak tespit etmiştir. Yıldız (2011) tarafından yapılan çalışmada, turşu örneklerinde tuz miktarı \%1.25-5.11 aralığında ve ortalama tuz miktarı \%3.66 olarak belirtilmiştir.

\subsection{Mikrobiyolojik bulgular}

Fasulye turşusu numunelerinde LAB 2.3-4.37 log kob/mL aralığında (ortalama $3.94 \log \mathrm{kob} / \mathrm{mL}$ ), TMAB 2.39-4.34 $\mathrm{kob} / \mathrm{mL}$ aralığında (ortalama $4.02 \log \mathrm{kob} / \mathrm{mL}$ ) ve maya sayısı 2-4.33 $\log \mathrm{kob} / \mathrm{mL}$ aralı̆̆ında (ortalama $3.98 \log \mathrm{kob} / \mathrm{mL}$ ) bulunmuştur (Çizelge 1). Karasu (2006) tarafından analizi yapılan turşu örneklerinde LAB $<3.00-7.80 \log \mathrm{kob} / \mathrm{mL}$, TMAB <3.00-8.28 log $\mathrm{kob} / \mathrm{mL}$ ve maya <3.00-7.85 log $\mathrm{kob} / \mathrm{mL}$ aralıklarında olacak şekilde sonuç vermiştir. Johanningsmeier ve ark. (2004) tarafından yapılan çalışmada ise LAB 3.65-7.97 $\log \mathrm{kob} / \mathrm{mL}$ aralığındadır. Yıldız (2011) yaptığı çalışmada turşu salamurası içerisinde TMAB sayısını 3.04-6.36 log kob/mL; LAB sayısını 5.81-8.09 log kob/mL aralığında ve maya sayısını $<1.00-7.20 \log \mathrm{kob} / \mathrm{mL}$ aralığında bulunmuştur. $\mathrm{Bu}$ referanslar doğrultusunda bu çalışma sonucunda elde edilen veriler yapılan çalışmaların sonuçlarına göre daha düşük bulunmuştur.

Çalışma verileri göz önünde bulundurularak yapılan karşılaştırmada $\mathrm{pH}$ değerleri farklı fakat \% tuz miktarları aynı 
olan 1 ve 2 numaralı numuneler arasında $\mathrm{kob} / \mathrm{mL}$ cinsinden mikroorganizma sayısının diğer test numunesine göre, daha asidik olan iki numaralı örnekte yüksek olduğu tespit edilmiştir. Aynı çalışmanın minimum ve maksimum \% tuz miktarına sahip olan 3 ve 4 numaralı numuneler arasında yapılan karşılaştırmada, 4 numaralı numunede $\mathrm{kob} / \mathrm{mL}$ cinsinden mikroorganizma sayısının yüksek olduğu tespit edilmiştir. Bir numaralı örneğin tüm mikroorganizma sayılarının diğer örneklerden daha düşük olduğu gözlenmiştir.
$\mathrm{Bu}$ durum, fermantasyon süresinin diğerlerinden farklı olmasından, diğerlerinden daha uzun zaman bekleyerek mikroorganizma canlılıklarını yitirmiş olmasından veya ilk mikroorganizma yüklerinin farklı olmasından kaynaklanmış olabilir.

Çizelge 1. Turşu numuneleri kimyasal ve mikrobiyolojik bulgular

\begin{tabular}{|c|c|c|c|c|c|}
\hline \multirow{2}{*}{$\begin{array}{c}\text { Numune } \\
\text { numaras1 }\end{array}$} & \multirow{2}{*}{ pH değeri } & \multirow{2}{*}{$\begin{array}{c}\text { Tuz miktar1 } \\
(\%)\end{array}$} & \multicolumn{3}{|c|}{$\begin{array}{c}\text { Mikroorganizma sayımlar1 } \\
\text { (log kob/mL) }\end{array}$} \\
\cline { 4 - 6 } & & & LAB & TMAB & Maya \\
\hline 1 & 3.64 & $\% 4.85$ & $2.30 \pm 0.00$ & $2.39 \pm 0.13$ & $2.00 \pm 0.00$ \\
\hline 2 & 3.52 & $\% 4.85$ & $3.93 \pm 0.03$ & $4.15 \pm 0.04$ & $4.07 \pm 0.07$ \\
\hline 3 & 3.40 & $\% 5.89$ & $3.50 \pm 0.03$ & $3.71 \pm 0.10$ & $3.70 \pm 0.15$ \\
\hline 4 & 3.65 & $\% 3.98$ & $4.37 \pm 0.03$ & $4.34 \pm 0.00$ & $4.33 \pm 0.04$ \\
\hline
\end{tabular}

\section{Sonuç}

Bilimsel literatürde Karadeniz yöresine has geleneksel fasulye turşusu ile ilgili yeteri kadar bilimsel veri yer almamaktadır. Bu çalışmada, 4 adet geleneksel fasülye turşusu kullanılarak salamuranın temel mikrobiyolojik ve biyokimyasal özellikleri belirlenmiştir. Örneklerin $\mathrm{pH}$ değerlerinin 3.40-3.65, tuz miktarlarının ise \%3.98-5.89 arasında değiştiği gözlenmiştir. Mikrobiyolojik analizler sonucunda, örneklerdeki laktik asit bakterileri sayısının 2.30-4.37 log kob/mL, toplam mezofilik aerobik bakteri sayısının 2.33-4.34 $\log \mathrm{kob} / \mathrm{mL}$, maya sayısının ise 2.00-4.33 $\log \mathrm{kob} / \mathrm{mL}$ arasında olduğu saptanmıştır. Değerler literatürde yer alan turşularla ilgili gerçekleştirilen diğer çalışmalarla uyumludur. İleride yapılacak çalışmalarda daha çok örnek kullanarak daha kapsamlı sonuçlar elde edilebilir. Ayrıca, salamura yanında fasulyeden de örnek alınması, ikisi arasında farklılık olup olmadığ1 konusunda bilgi verecektir. Elde edilen mikroorganizmaların saflaştırılarak tanımlanması, bu turşu çeşidine spesifik mikroorganizma profilinin ortaya konmasını sağlayacaktır. Bu çalışma, daha kapsamlı çalışmalar için bir başlangıç teşkil etmektedir.

\section{Kaynaklar}

Akman, A. (1987). Türkiye'de fermantasyon teknolojisinin gelişim öyküsü. Gıda, 12(3). 145-150.

Anlarsal, A. E., Yücel, C., \& Özveren, D. (2000). Çukurova koşullarında bazı fasulye (Phaseolus vulgaris L.) çeşitlerinde tane verimi ve verimle ilgili özellikler ile bu özellikler arası ilişkilerin saptanması. Turkish Journal of Agriculture and Forestry, 24(1), 19-29.

Çavuşoğlu, A., \& Akçin, A. (2007). Taze fasulye (Phaseolus vulgaris L.) çeşitlerinde farklı gübre kombinasyonlarının verim ve verim unsurları üzerine etkileri. Selcuk Journal of Agriculture and Food Sciences, 21(43), 106-111.

Johanningsmeier, S. D., Fleming, H. P., \& Breidt Jr, R. (2004). Malolactic activity of lactic acid bacteria during sauerkraut fermentation. Journal of Food Science, 69(8), M222-M227.
Karaçil, M. Ş., \& Nilüfer, A. C. A. R. (2013). Dünyada üretilen fermente ürünler: Tarihsel süreç ve sağlık ile ilişkileri. Uludağ Üniversitesi Ziraat Fakültesi Dergisi, 27(2), 163-174.

Karagöz, Ö. G. Ş., \& Güllü, M. (2017). Türk kültüründe kış hazırlıkları; turşu türlerinin ve üretim metotlarının değerlendirilmesi. Al-Farabi International Journal on Social Sciences, 2(M), 95-105.

Karasu, N. (2006). Turşu ve zeytinden antagonistik ve probiyotik özellikte laktik starter kültür eldesi (Yüksek lisans tezi, Pamukkale Üniversitesi).

Kumral, A. (2005). Salamura siyah zeytin üretiminde farklı tuzda ve düşük sicaklıkta fermentasyon uygulamasının olgunlaşma ve kaliteye etkisi (Doktora Tezi, Uludağ Üniversitesi).

Tokatlı, M., Dursun, D., Arslankoz, N., Şanlıbaba, P., \& Özçelik, F. (2012). Turşu üretiminde laktik asit bakterilerinin önemi. Akademik Gıda, 10(1), 70-76.

Tokatlı, M., Elmacı, S. B., İşleyen, N. A., \& Özçelik, F. (2019). Seçilmiş endojen laktik starter kültürler ile turşu üretimi. Gida, 44(4), 742-757.

TSE 1990. Lahana turşusu, Türk Standartları Enstitüsü, TS4200, Ankara.

TSE 1993. Hıyar turşusu, Türk Standartları Enstitüsü, TS11112, Ankara.

TSE 2015. Karışık turşu, Türk Standartları Enstitüsü, TS4214, Ankara.

Ulukapı, K., \& Onus, A. N. (2013). Selekte edilmiş bazı yerel taze fasulye (Phaseolus vulgaris L.) genotiplerinin moleküler karakterizasyonu. Tarım Bilimleri Dergisi, 18, 277-286.

Yıldız, H. (2011). Turşu ve zeytinlerden laktik asit bakterileri ile mayaların izolasyonu, identifikasyonu ve elde edilen izolatların bazı özelliklerinin belirlenmesi (Doktora tezi, Atatürk Üniversitesi). 